\title{
Sustainable education in the context of continuous technology update
}

\author{
Roman Yavich ${ }^{1}$, Boris Bortnik ${ }^{2}$, Natalia Stozhko ${ }^{2, *}$, Natalia Sudakova ${ }^{2}$, and Dmitrii \\ Stozhko ${ }^{2}$ \\ ${ }^{1}$ Ariel University, Ramat HaGolan Str., 65, 4077625 Ariel, Israel \\ ${ }^{2}$ Ural State University of Economics, 8 Marta Str., 62, 620144 Ekaterinburg, Russia
}

\begin{abstract}
The paper discusses the problem of the sustainable functioning of the educational system in the context of the intensive development of information technologies, which is urgent in Russia and, practically, in other countries throughout the world. It has become especially acute in recent years in connection with the forced transition to a large-scale organization of distance learning. Based on the analysis of the cultural and historical process in Russia, the most important traditions and features of Russian education are identified, which ensured its sustainable development and world recognition of a high level of quality. The radical economic and social changes at the end of the twentieth century, their consequences and impact on education are considered. The authors point to a number of factors that play a significant role in the development of the education system, determining its flexibility and sustainability. Special attention is paid to modern trends in the development and use of information technologies in education in the context of digitalization of the economy, including distance learning, and the open education system. New objective possibilities are compared that should contribute to the formation of an innovative educational environment of the university, intellectualization of the educational process, and problematic aspects that require detailed study. The authors classify these problems. The directions of their solution are outlined.
\end{abstract}

\section{Introduction}

For many years, the Russian educational system has been subject to changes of various scales. Their goals and results are controversial. The latest example is the widespread adoption of distance learning, driven by the pandemic. It has radically transformed the technological and organizational aspects of educational activities and has so far barely affected the content. The consequences of this forced experiment are not yet clearly visible, but there is no doubt that they will have an impact on the sustainability of the education system. The problem of sustainability is inextricably linked with change and becomes especially acute when change is significant in scale and pace, as in recent times. It is relevant both here and abroad. [1,2]. The rapid development and continuous change of

\footnotetext{
* Corresponding author: sny@usue.ru
} 
technologies, first of all, information technologies, directly affect the education system, especially higher education, causing a number of contradictions. These contradictions, to varying degrees of severity, take place in almost all countries. In particular, the variety of technologies and their rapid obsolescence do not correlate with the adopted terms of study, the technological competence of a significant contingent of teachers, based on previous technologies, does not meet the needs of students and society as a whole. [3], to a certain extent, the interests of education and science are opposite to the interests of business [4]. Probably the most significant in the context of the problem of sustainability of education is the contradiction between the global and current goals of education. The history of the development of secular education, starting from the Renaissance, shows quite convincingly that it is mainly aimed at the formation of intelligence - personal and social - which is characterized by deep versatile knowledge, the ability to use it to optimally solve various problems, the need and skills of continuous self-improvement. This is precisely the constant global goal of education, which determines all aspects of the educational process, and, above all, meaningful. Actual goals are dynamic, changeable, (sometimes, to inversion), they correspond to actual social and economic challenges, needs due to a specific technological order. These two types of goals form a dialectical unity, which is one of the most important system-forming factors. Touching upon the problem of sustainability of education, it is necessary to determine what it is - sustainability - it is, how it relates to reform and development, on what factors and how it depends. Discussion of these questions is included in the tasks of this work.

\section{Methodology}

The subject of study and discussion is the field of education and the modern educational environment of the university. The methodology of this work is based on cultural-historical, system-evolutionary and economic-sociological approaches. From these positions, education is viewed as an open evolving system, on the one hand, reflecting the course of development of the economy and civilization as a whole, on the other hand, significantly influencing this development. The educational environment of the university as part of the educational system forms highly intellectual and highly qualified human capital, which is the most important resource and element of national wealth, on which the well-being of society depends significantly. Synergistically interacting components of this environment consistently ensure the achievement of educational goals.

\section{Results and discussion}

Sustainable education predetermines the sustainable development of a civilized society, i.e. such a long-term harmonious, balanced development, in which progressive technological, economic, social, institutional transformations are carried out in a coordinated, ecologically rational manner, taking into account not only the actual, but also the future needs of society. The sustainability of education directly depends on the balance of global and actual goals, which is determined by social needs arising in the historically determined course of development. This balance affects the pace of development of the educational system and sustainability in relation to various kinds of challenges. The former, pre-revolutionary Russian educational system and its direct successor (in spite of all the innovations) - the Soviet one - was, to a certain extent, characterized by such sustainability. It should be emphasized that the factor of continuity is significant enough to ensure the sustainability of the development of education. Continuity was manifested in the fundamental nature of programs, traditional for Russia, at all levels of education, including in higher education. 
Fundamental disciplines, including mathematical and natural sciences, which at that time were at the forefront of the development of science, traditionally occupied a prominent place in these programs for training specialists for many industries.

Fundamentality presupposes knowledge based on experimental and theoretical studies of the fundamental processes and phenomena in nature and society, the identification and understanding of the laws governed by these processes, the basic principles and tools of the most important disciplines. Fundamentality does not imply the obligatory fast cost-effective practical implementation of knowledge. On the contrary, implementation, as a rule, is relatively distant, but gives a tangible effect, often leading to a technological revolution and radical changes in the worldview. The fundamental character of Russian education in the 20th century was especially clearly expressed. It provided a high level of intellectual potential, professional mobility and, in general, the competitiveness of specialists, which was repeatedly noted both in the media and in scientific publications. During this period, the development of the fundamental sciences that underlie scientific and technological progress had significant public and state support, scientific rationalism and the scientific worldview based on it occupied a special place among the priority cultural values. They were passed down from generation to generation through the sustainable education system and translated this sustainability.

In the second half of the 20th century, the world enters the era of informatization - the beginning of the fifth technological order. Information technologies are becoming a necessary toolkit for all spheres of life. A new technological revolution is taking place, which gives mankind a powerful apparatus for quickly solving a wide (practically unlimited) range of tasks, receiving, processing, storing and transmitting huge amounts of information, and implementing a lot of qualitatively new functions that are not typical for a person without this toolkit. It should be emphasized that informatics is the result of a synergistic symbiosis of mathematics, physics, and their offspring - cybernetics, genetically inherits the fundamental nature of these disciplines, especially since it has the goal of forming artificial intelligence. With the introduction of information technologies in the field of education, its capabilities, tasks and relationships of all participants in the educational process have changed significantly. In the last decade of the twentieth century, the world is globalized by the Internet, which has eliminated the role of the spatial factor in broadcasting information and has become a platform for distance learning. All this led to a change in the paradigm of education that took place in many countries at the end of the twentieth century.

In Russia, these changes are taking place in the "era of perestroika". With the development of a market economy, almost all spheres of culture, including science and education, are commercialized. In the course of the educational reform, which began in the 90s and intensified with the accession of Russia to the Bologna Convention, there is a continuous change in state educational standards developed within the framework of the competence-based approach approved by the law on education. The succession factor is noticeably weakened. At the same time, the ratio of global and current educational goals is changing in favor of the latter. It is the implementation of current goals that is provided for by the formulations of competencies that university graduates should receive. The extensive list of these competencies covers a large number of professional options, including the ability to use specific modern technologies. But technology is changing rapidly. And for the sustainable functioning of education that ensures sustainable development, it is advisable to provide a significant emphasis on the fundamental principles of creating these technologies, which would effectively contribute to the continuous self-improvement of specialists.

In this regard, it is appropriate to dwell in more detail on information technologies, digitalization, their role in modern education and in relation to the subject. At present, in accordance with the Strategy for the Development of the Information Society in Russia for 
2017-2030, approved by the decree of the President of the Russian Federation in 2017, a course has been taken to digitize the economy. This trend automatically carries over to education, and is discussed in many publications and documents in recent years. Certainly, the question arises about the relationship between the similar terms "informatization" and "digitalization", on which there are different points of view. Without evaluating their numerous interpretations, without putting a sign of equivalence and without analyzing the differences, in the context of this work, different ones should be considered. including, problematic aspects of the influence of these processes on personality development and on the sustainability of education.

Informatization has provided all subjects of the educational process with a huge information field and numerous technologies for working in it. Mastering these technologies, independent search for information and its comprehension, the creation on this basis of various projects, including interdisciplinary $[5,6]$, setting and solving problems using new tools $[7,8]$, work in virtual and real environments using one of them for deeper mastering of the other [9], design of the resulting solutions in the form of virtual models, their mental interpretation using logical operations (analysis and synthesis, induction and deduction, etc.), the interactive interaction of all participants provides a qualitatively new intellectualization of students and educators [10]. Informatization has radically changed the infrastructure of the education sector and its management. Thus, at a new level, the conditions for movement towards the global goal of education are realized, revealing the fundamentalization and potential of sustainable development.

At the same time, there are problems that significantly slow down this movement. Informatization has led to the rapid development and spread of distance learning and open education (primarily higher education) [11]. Education has become accessible and widespread. At the same time, the availability of distance learning in Russia is mainly determined by the commercial interests of universities. If, when enrolling full-time students, there is a noticeable competitive selection, then the distance form is available to almost everyone who has paid for training, regardless of the level of preparedness for it. Moreover, the higher the mass, the lower the fee. So in general, such mass training is relatively inexpensive. This negatively affects the quality of education. In previous years, it was also lower in correspondence than in full-time, but now the differences are not comparable with the same educational standards and programs. The quality level is not sufficiently monitored and taken into account by employers when selecting personnel. Although they are interested in well-trained specialists, the results of training, reflected not only by grades in a five-point system, but, in fact, in a three-point system (a grade below 3 is not given) are not really taken into account. The rating system works only within the university, and that is not very effective, because the students are not very serious about it and the teachers are not very responsible.

Accessibility is typical for any information, including the results of assignments received by students. Here it is often the teachers themselves who are "to blame", who are unable or do not give themselves the trouble to formulate assignments in such a way that its implementation is not directly borrowed from the Internet. In justification of the teacher, it can be noted that in the conditions of such a mass education and, accordingly, an excessive teaching load and an unreasonably high "hidden" load (laborious reformatting of methodological support in accordance with the constantly changing requirements of administrative bodies), he has no time to really engage in self-improvement, increase the level of knowledge of information technologies (for a significant part of teachers it does not meet current requirements, and not only in Russia, but also in other countries [12], including Israel, which is in the "top 10 " of the most "digital" countries), pedagogical creativity and - specifically - the processing of educational materials, and previously developed tasks and the results of their implementation are very quickly in the open (or 
almost open) access. The problem of overloading Russian teachers in comparison with foreign colleagues is quite old, it is constantly discussed, but its acuteness is only increasing. One more problem, although perhaps not the most significant with the abundance of various computing tools and mathematical programs, is a clear decline in mathematical literacy. Many modern specialists not only do not know how to count, but also do not have sufficient knowledge of calculation devices in their professional field, having completely transferred the corresponding functions to computers, in fact becoming operators. It is these moments that underlie the predictions that in the not too distant future a number of not very creative professions (which mainly involve working according to a given algorithm) will disappear. A separate problem is associated with the socialization of the individual. This is the problem of open education. Without discussing its unfinished legal (regulatory), medical, financial and other aspects, it should be noted that the opportunity to get one-on-one education with a computer, without direct contact with teachers and other students, affects personality formation, which was revealed by a number of studies [13,14]. All this reduces the effectiveness of the positive aspects of informatization (digitalization) of education and does not allow us to speak unambiguously about intellectualization and sustainable progressive development. Obviously, it is advisable to regulate the use of the opportunities of the information age in education, taking into account the achievements of traditional pedagogy and psychology.

Summarizing the above, the following factors can be identified that ensure the fundamental and sustainable development of the education system:

- the unity of global goals, providing for the formation of intelligence as the basis for self-improvement and long-term stable development, and relevant ones, taking into account the nearest prospects, with the dominance of the first ;

- fundamental nature of educational programs;

- a high level of quality regardless of the form of training and the scale of educational activity;

- continuity in reforming, a reasonable combination of new educational technologies with traditional ones, optimization of the use of information technologies;

- effective relationship of educational institutions with employers, the latter's real interest in high rates of learning outcomes;

- creation of real conditions for creative activity and self-improvement of teachers, increasing the level of their IT competence.

These factors, on the one hand, determine the formation of the educational environment of a modern university, on the other, through this environment in each institution - the formation of the entire system of higher education (and education in general). A model of such an environment was proposed and discussed by the authors earlier. [15]. It is appropriate to emphasize here that complex synergistic relationships between the components of this environment are provided by its infrastructure, the optimal management of which is achieved on the basis of digitalization. If the use of this term in relation to the entire education system as a whole is controversial, then in relation to infrastructure management in the context of the adopted development strategy there is no doubt. It is the digital system that is already capable of solving problems posed by a person practically independently of him, comparing various options for solutions according to given criteria and making an optimal choice. This functionality is hardly appropriate in the implementation of the content components of the educational environment, but it is effective for the implementation of management, defining the innovative nature of its development. 


\section{Conclusion}

In the context of continuous updating of information technologies and the implementation of a course on digitalization of the economy, its sustainable development is inextricably linked with the stability and flexibility of the education system, the adaptability and innovativeness of the educational environment of each university. Analysis of the polar aspects of intensive informatization of education shows that achieving its sustainability requires solving a number of significant problems: strategic (balancing educational goals, adjusting the content in accordance with the goals, technologies, requests of all stakeholders, including employers and taking into account the long-term perspective), methodological (optimal the use of modern tools not to the detriment of solving psychological and pedagogical problems), legal (development of a regulatory framework for an open education system, regulation of changing relationships of all participants in the process), personnel (formation of an effective system of technological retraining of teachers, creating real conditions for their self-improvement), organizational (unity approaches to assessing the quality of all forms of education, developing a system for accounting for its importance in the labor market). It is impossible to solve these problems once and for all, but every step in solving them is a movement along the trajectory of sustainable development.

\section{References}

1. S. Looser, S. Mohr, Int. J. Manag. Educ., 18 (2020)

2. L. Noordegraaf-Eelens, J. Kloeg, G. Noordzij, Adv. Health Sci. Educ., 24 (2019)

3. F. Caena, C. Redecker, Eur. J. Educ., 54 (2019)

4. J. A. Kemper, P. W. Ballantine, C. M. Hall, J. Clean. Prod., 271 (2020)

5. W.F. Crittenden, I.K. Biel, W.A. Lovely, J. Market Educ., 41 (2019)

6. D. Orr, M. Weller, R. Farrow, JIME, 41 (2019)

7. N. Stozhko., B. Bortnik, L.Mironova, A. Tchernysheva, E. Podshivalova, RLT, 23 (2015)

8. E. E. Virtue, B. N. Hinnant-Crawford, IJPBL, 13 (2019)

9. B. Bortnik, N. Stozhko, I. Pervukhina, A. Tchernysheva, G. Belysheva, RLT, 25 (2017)

10. I. V. Robert, I. S. Mukhametzyanov, A. A. Arinushkina, A. A., Kastornova, L. P. Martirosyan, Espacios, 38 (2017)

11. G. Gomez-Zermeno, M. Gomez-Zermeno, JSDEWES, 8 (2020)

12. A. B. Mirete, J. J. Maquilon,, L. Mirete, A. R. P. Raimundo, Sustainability, 12 (2020)

13. N. Davidovitch, R. Yavich, Probl. Educ. 21st Century, 76 (2018)

14. N. Bergdahl, J. Nouri, U. Fors, Educ. Inform. Tech., 25 (2020)

15. D. K. Stozhko, B. I. Bortnik, N. Yu. Stozhko, Proc. SICNI 2018, ASSEHR 240, (2019) 